\title{
Ege Üniversitesi Hastanesinde gastrointestinal sistem kanserlerinin epidemiyolojik ve sağ kalım özellikleri
}

\section{Epidemiological and survival characteristics of gastrointestinal cancers in Ege University Hospital database}

\author{
Ayfer Haydaroğlu ${ }^{1} \quad$ Deniz Yalman ${ }^{1} \quad$ Sinan Ersin $^{2}$ \\ Bülent Karabulut $^{5} \quad$ Nalan Ünal $^{6} \quad$ Ömer Özütemiz ${ }^{6}$ \\ Başak Doğanavşargil Yakut ${ }^{3,4}$ \\ ${ }^{1}$ Ege Üniversitesi Tıp Fakültesi Radyasyon Onkolojisi Anabilim Dalı, İzmir, Türkiye \\ ${ }^{2}$ Ege Üniversitesi Tıp Fakültesi Genel Cerrahi Anabilim Dalı, İzmir, Türkiye \\ ${ }^{3}$ Ege Üniversitesi Tıp Fakültesi Patoloji Anabilim Dalı, İzmir, Türkiye \\ ${ }^{4}$ Ege Üniversitesi Kanserle Savaş Araştırma ve Uygulama Merkezi (EÜKAM), İzmir, Türkiye \\ ${ }^{5}$ Ege Üniversitesi Tıp Fakültesi İç Hastalıkları Anabilim Dalı Medikal Onkoloji Bilim Dalı, İzmir, Türkiye \\ ${ }^{6}$ Ege Üniversitesi Tıp Fakültesi İç Hastalıkları Anabilim Dalı Gastroenteroloji Bilim Dalı, İzmir, Türkiye
}

\section{Öz}

Amaç: Ege Üniversitesi Hastanesi (EÜH)'nde 1992-2017 arası gastrointestinal sistem (GiS) kanseri tanısı ve tedavileri yapılan olguların epidemiyolojik ve genel sağ kalım (GSK) özelliklerinin değerlendirilmesidir.

Gereç ve Yöntem: EÜKAM tarafından 1992-2017 yılları arasında 19.542 GIS kanser kaydı yapılmıştır. Sınıflandırmalarda ve sağ kalım analizlerinde SEER verileri göz önüne alınmıştır. CANREG 4 programı ile kaydedilen veriler SPSS programına aktarılmış, istatistik analizde Ki-kare yöntemi ve doğrusal modellemeler yapılmış, $p<0,05$ değeri anlamlı kabul edilmiştir.

Bulgular: GiS kanserleri, tüm olgularda ilk sırada $(\% 16,7)$ yer almaktadır $(p<0,0001)$, erkeklerde ikinci, kadınlarda üçüncü sıradadır. GíS kanserleri içinde en sık kolorektal kanserler (KRK) (\%37), mide (\%22) ve pankreas (\%13) kanseri izlenmektedir. KRK kadınlarda $(\% 38,6)$, mide kanserleri ise erkeklerde $(\% 22,6)$ daha sıktır $(p<0,0001)$. Yerleşimler, cinsiyet ve yaş grupları dikkate alındığında, Gis kanserleri erkeklerde $60-69$ yaş grubunda (\%31), kadınlarda $>70$ yaş grubunda $(\% 28,6)$ anlamlı yüksektir (ki-kare: 85,297; p<0,0001). Yirmi yaş ve üzeri erişkin ve çocukluk dönemi kanser yerleşimleri karşılaştırıldığında, çocuklarda karaciğer ve intrahepatik safra yolları $(\% 60,9)$, erişkinde KRK ilk sıradadır $(\% 37,4) \quad(p<0,00019)$. Histopatolojik olarak en sık adenokanserler $(\% 70)$ görülmektedir $(p<0,0001)$. GiS kanserlerinde yıllara göre doğrusal bir artış saptanmıştır $(p<0,0001)$.

Sonuç: EÜH Kanser Kayıt sisteminde GiS kanserleri tüm sistemler arasında birinci sıradadır. GiS kanserleri içinde en sık KRK görülmekte, bunu mide kanserleri izlemektedir. KRK kadınlarda, mide kanseri erkeklerde daha sıktır. GiS kanserleri hastanemizde cinsiyete ve yıllara göre doğrusal bir artış göstermektedir. GiS kanserlerimizde ortalama sağ kalım 25 ay, beş ve 10 yıllık GSK oranları \%33,6 ve $\% 25,2$ 'dir.

Anahtar Sözcükler: Gastrointestinal kanserler, epidemiyoloji, sağ kalım, insidans, mortalite.

\footnotetext{
Abstract

Yazışma Adresi: Ayfer Haydaroğlu

Ege Üniversitesi Tıp Fakültesi, Radyasyon Onkolojisi

Anabilim Dalı

E-mail:haydaroglua@gmail.com
}

Aim: The aim of the study was to evaluate the epidemiological and overall survival (OS) characteristics of patients with gastrointestinal system (GIS) cancer in Ege University database. 
Materials and Methods:19.542 GIS cancers were registered by EUKAM between 1992-2017 years. SEER data were taken into account for classifications and analyzes. Data recorded by CANREG 4 program were transferred to SPSS program, the chi-square test and linear modeling were used for statistical analysis, $p<0.05$ value was considered significant.

Results: GIS cancers are the most common cancers (16.7\%), 2. in men and 3. in women in all cases $(p<0.0001)$. Colorectal $(C R C)(37 \%)$, gastric (22\%) pancreatic (13\%) cancers are the most common types of GIS cancers respectively. CRC was more common in women (38.6\%), gastric cancers were more common in men (22.6\%) ( $p$ <0.0001). GIS cancers were significantly higher in the 60-69 age group (31.0\%) for males and over 70 years (28.6\%) for women (chi-square: 85.297; $p<0.0001)$. Liver and intrahepatic bile ducts (60.9\%) were the most common localization in children (20.9\%) and CRC $(37.4 \%)$ in adults $(p<0.00019)$. Adenocarcinoma was the most common histopathological type (70\%). There was a linear increase in GIS cancers over the years $(p<0.0001)$.

Conclusion: In the EUKAM database, GIS cancers are the most common cancers. CRC is the most common type among GIS cancers followed by gastric cancers. CRC is more common in women; gastric cancer is more common in men. There is a linear increase in GIS cancers over the years. Median survival is 25 months, 5- and 10-years OS rates are $33.6 \%$ and $25.2 \%$.

Keywords: Gastro-intestinal cancer, epidemiology, survival, incidence, mortality.

\section{Giriş}

Gastrointestinal sistem (GiS) kanserleri solunum sistemi kanserlerinden sonra ikinci sıklıkla görülmektedir (1). GiS kanserleri içindeki kanser yerleşimleri coğrafi konuma göre değişkenlik göstermektedir. Mide kanserleri Japonya'da daha sık iken kolorektal kanserler (KRK) ABD'de daha sık görülmektedir. Türkiye verilerinde de dünya istatistiklerine paralel olarak solunum sistemi kanserlerinden sonra ikinci sırada yer almaktadır. Gis kanserlerinde, yerleşimlere göre erkeklerde mide, kadınlarda KRK ön plandadır (2).

$\mathrm{Bu}$ makalenin amacı; Ege Üniversitesi Hastanesinde (EÜH), 1992-2017 yılları arasında GiS kanseri tanı ve tedavisi yapılan 19.542 olgunun epidemiyolojik ve genel sağ kalım (GSK) özelliklerinin ana hatlarla ortaya konmasıdır. GiS organ kanserlerine göre hasta özellikleri, yapılan tedaviler ve hasta özelliklerine ve tedavilerine göre sağ kalımlar ayrı makalelerde sunulacaktır. Bu çalışma Ege Üniversitesi Tıbbi Araştırmalar Etik Kurulu tarafından onaylanmış ve multidisipliner hazırlanmış olup 23. Ulusal Kanser kongresinde sunulmuştur.

\section{Gereç ve Yöntem}

Ege Üniversitesi Kanserle Savaş Araştırma ve Uygulama Merkezinin (EÜKAM) özel eğitimli ve sertifikalı kanser kayıt elemanları tarafından
1992-2017 yılları arasında, EÜH'de 19.542 GiS kanseri kaydı yapılmıştır. Sınıflandırmalarda ve sağ kalım analizlerinde SEER verileri göz önüne alınmıştır. CANREG 4 programı ile kaydedilen veriler SPSS programına aktarılmış, istatistik analizde $\mathrm{Ki}$ kare testi ve doğrusal modellemeler yapılmış, $p<0,05$ değeri anlamlı kabul edilmiştir. Olgular, gastroenteroloji kliniğinde tanı alan ve hastanemizde ameliyat olan veya dışarıda tanı alıp radyoterapi ve kemoterapi gibi tedavilerini hastanemizde alan Gis kanserli hastalardır. Çalışma istatistikleri EÜKAM istatistik ve bilgisayar uzmanı Ömer Karaca tarafından yapılmıştır.

\section{Bulgular}

EÜKAM tarafından, 1992-2017 arası 25 yıl içinde EÜH'de 117.139 kanser verisi toplanmıştır. Toplanan bu verilerin içinde 19.542'si Gis kanseridir. EÜH Kanser Kayıt sisteminde GiS kanserleri tüm olgularda ilk sırada $(\% 16,7)$ yer almaktadır (Ki-kare:61,189; $\mathrm{p}<0,0001)$. Erkeklerde ikinci, kadınlarda üçüncü sırada GiS kanserleri görülmektedir (Tablo-1, Şekil-1). Gis kanserleri içinde en sık KRK görülmekte $(\% 37,3)$, bunu mide $(\% 21,6)$ ve pankreas $(\% 12,8)$ kanseri izlemektedir (Tablo-2, Şekil-2). 
Tablo-1. Ege Üniversitesi Hastanesinde sistemlere göre1992-2017 kanser verileri.

\begin{tabular}{|c|c|c|c|c|c|c|}
\hline \multirow{2}{*}{ Sistemlere Göre Dağılım } & \multicolumn{2}{|c|}{ Erkek } & \multicolumn{2}{|c|}{ Kadın } & \multicolumn{2}{|c|}{ Toplam } \\
\hline & $\mathbf{n}$ & $\%$ & $\mathbf{n}$ & $\%$ & $\mathbf{n}$ & $\%$ \\
\hline GiS* & 11.923 & 19,4 & 7.619 & 13,7 & 19.542 & 16,7 \\
\hline Solunum Sistemi (Akciğer) & 12.507 & 20,3 & 1.745 & 3,1 & 14.252 & 12,2 \\
\hline Baş ve Boyun & 7.225 & 11,7 & 8.176 & 14,7 & 15.401 & 13,1 \\
\hline Meme & 170 & 0,3 & 12.909 & 23,2 & 13.079 & 11,2 \\
\hline Cilt & 5.608 & 9,1 & 4.293 & 7,7 & 9.901 & 8,5 \\
\hline Kadın Genital & - & - & 8.332 & 15,0 & 8.332 & 7,1 \\
\hline Hematopoetik, RES & 3.739 & 6,1 & 2.924 & 5,3 & 6.663 & 5,7 \\
\hline MSS & 2.949 & 4,8 & 2.928 & 5,3 & 5.877 & 5,0 \\
\hline Üriner Sistem & 4.744 & 7,7 & 1.288 & 2,3 & 6.032 & 5,1 \\
\hline Erkek Genital & 5.634 & 9,2 & - & - & 5.634 & 4,8 \\
\hline Lenf Bezleri & 2.298 & 3,7 & 1.623 & 2,9 & 3.921 & 3,3 \\
\hline Primeri Bilinmeyen Tümörler & 2.083 & 3,4 & 1.432 & 2,6 & 3.515 & 3,0 \\
\hline Kemik-Eklem & 813 & 1,3 & 569 & 1,0 & 1.382 & 1,2 \\
\hline Bağ Dokusu & 942 & 1,5 & 837 & 1,5 & 1.779 & 1,5 \\
\hline Nadir Tümörler & 919 & 1 & 910 & 2 & 1.829 & 1,6 \\
\hline Toplam & 61.554 & 100 & 55.585 & 100 & 117.139 & 100 \\
\hline
\end{tabular}

"ki-kare: 61,$189 ; p<0,0001$

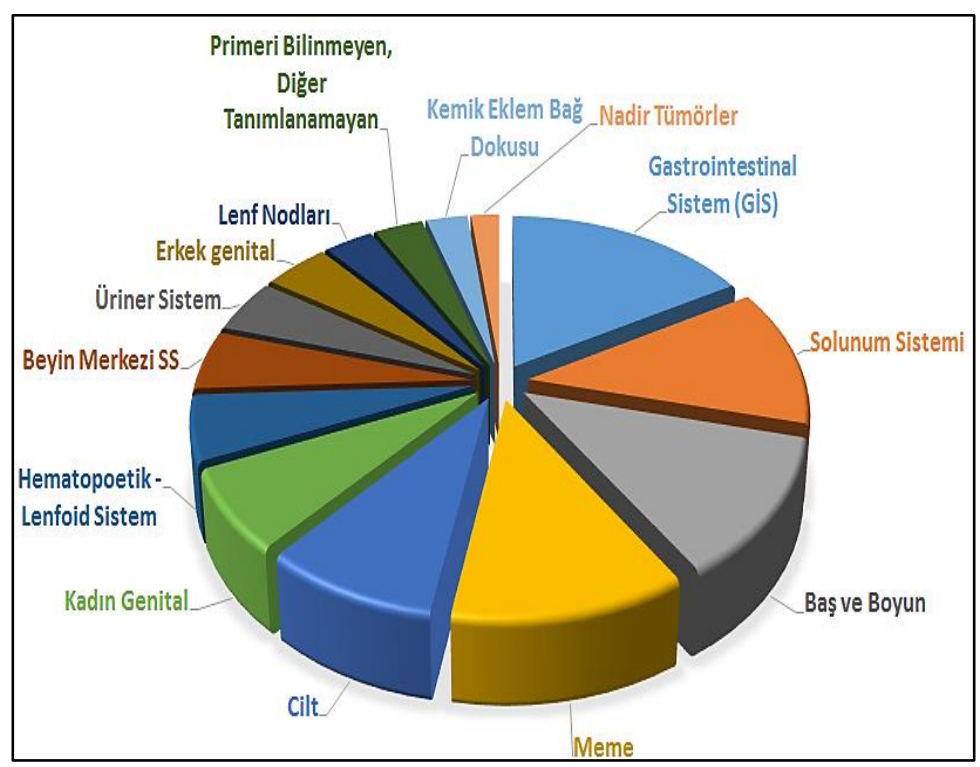

Şekil-1. Ege Üniversitesi Hastanesi kanser verilerinde sistemlere göre dağılım.

Tablo-2. GiS kanserlerinde yerleşim.

\begin{tabular}{lll}
\hline GiS Yerleşim & $\mathbf{n}$ & $\%$ \\
\hline Kolorektal & $\mathbf{7 . 2 8 5}$ & $\mathbf{3 7 , 3}$ \\
Mide & 4.212 & 21,6 \\
Özofagus & 1.009 & 5,2 \\
Ince Barsak & 287 & 1,5 \\
Anal Kanal ve Anüs & 126 &, 6 \\
Karaciğer ve İntrahepatik Safra Kanalları & 2.272 & 11,6 \\
Safra kesesi ve Ekstrahepatik Safra Kanalları & 1.569 & 8,0 \\
Pankreas & 2.507 & 12,8 \\
Appendiks ve Diğer Gis & 275 & 1,4 \\
Toplam & $\mathbf{1 9 . 5 4 2}$ & $\mathbf{1 0 0 , 0}$ \\
\hline
\end{tabular}




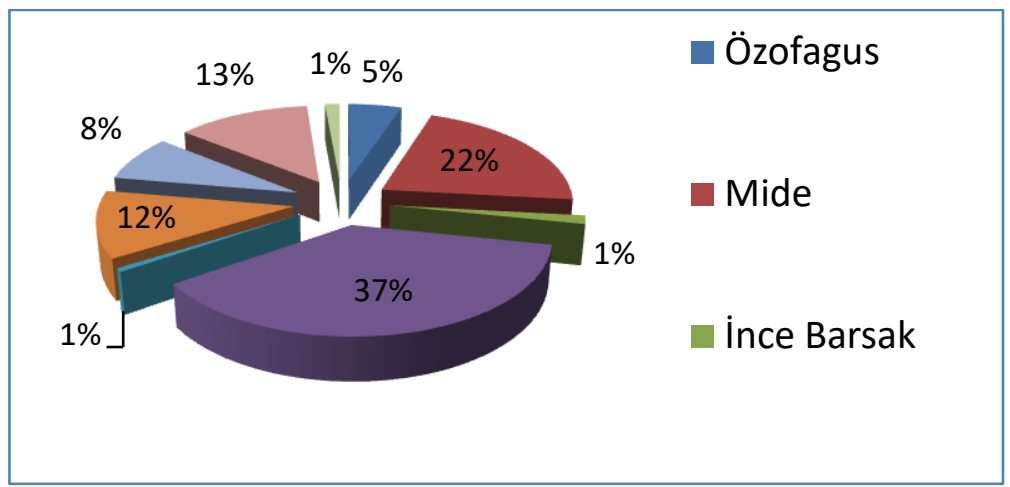

Şekil-2.GiS kanserlerinde yerleşim dağılımı.

Kolorektal kanserler kadınlarda $(\% 38,6)$ erkeklerden $(\% 36,5)$; mide kanserleri ise erkeklerde $(\% 22,6)$ kadınlardan (\%20) anlamlı yüksektir (Ki-kare:196,497; p<0,0001) (Tablo-3, Şekil-3).

Tablo-3. Cinsiyetlere göre GiS kanserlerinin dağılımı.

\begin{tabular}{|c|c|c|c|c|c|c|}
\hline \multirow{2}{*}{ Yerleşim } & \multicolumn{2}{|c|}{ Erkek } & \multicolumn{2}{|c|}{ Kadın } & \multicolumn{2}{|c|}{ Toplam } \\
\hline & $\mathbf{n}$ & $\%$ & $\mathbf{n}$ & $\%$ & $\mathbf{n}$ & $\%$ \\
\hline Özofagus & 573 & 4,8 & 436 & 5,7 & 1.009 & 5,2 \\
\hline Mide & 2.692 & 22,6 & 1.520 & 20 & 4.212 & 21,6 \\
\hline İnce Barsak & 178 & 1,5 & 109 & 1,4 & 287 & 1,5 \\
\hline Kolorektal & 4.347 & 36,5 & 2.938 & 38,6 & 7.285 & 37,3 \\
\hline Anal Kanal ve Anüs & 54 & 0,5 & 72 & 0,9 & 126 & 0,6 \\
\hline Karaciğer ve İHSY & 1.627 & 13,6 & 645 & 8,5 & 2.272 & 11,6 \\
\hline Safra kesesi ve EHSY & 808 & 6,8 & 761 & 10 & 1.569 & 8 \\
\hline Pankreas & 1.493 & 12,5 & 1.014 & 13,3 & 2.507 & 12,8 \\
\hline Appendiks ve Diğer Gis & 151 & 1,3 & 124 & 1,6 & 275 & 1,4 \\
\hline Toplam & 11.923 & 100 & 7.619 & 100 & 19.542 & 100 \\
\hline
\end{tabular}

IHSY: intrahepatik safra yolları, EHSY: ekstrahepatik safra yolları.

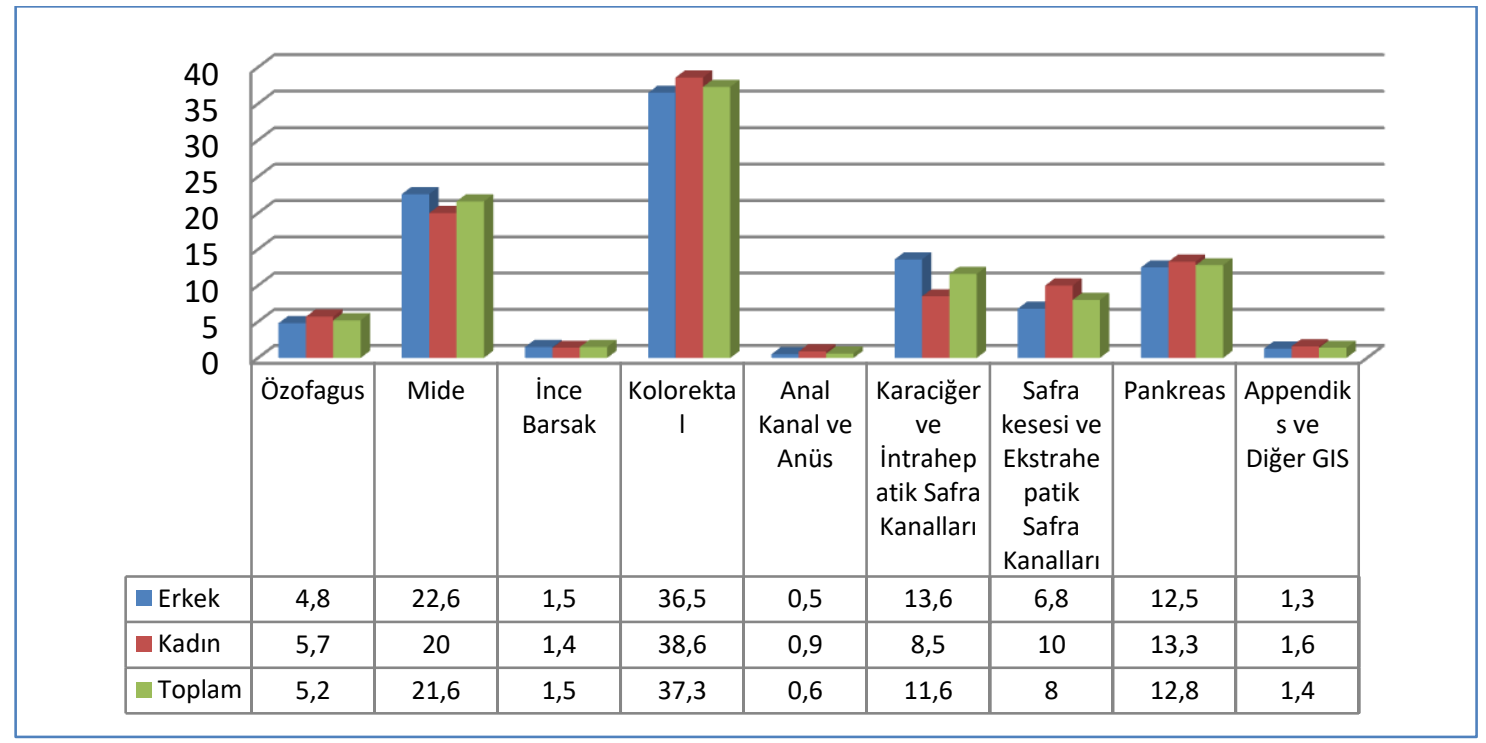

Şekil-3. Cinsiyetlere göre GíS kanserlerinin yüzde dağılımı. 
Yerleşimlerin cinsiyet ve yaş gruplarına göre dağılımında Gis kanserleri erkeklerde 60-69 yaş grubunda (\%31), kadınlarda ise 70 yaş üzeri grupta $(\% 28,6)$ anlamlı yüksektir (Ki-kare:85,297; $\mathrm{p}<0,0001)$ (Şekil-4).

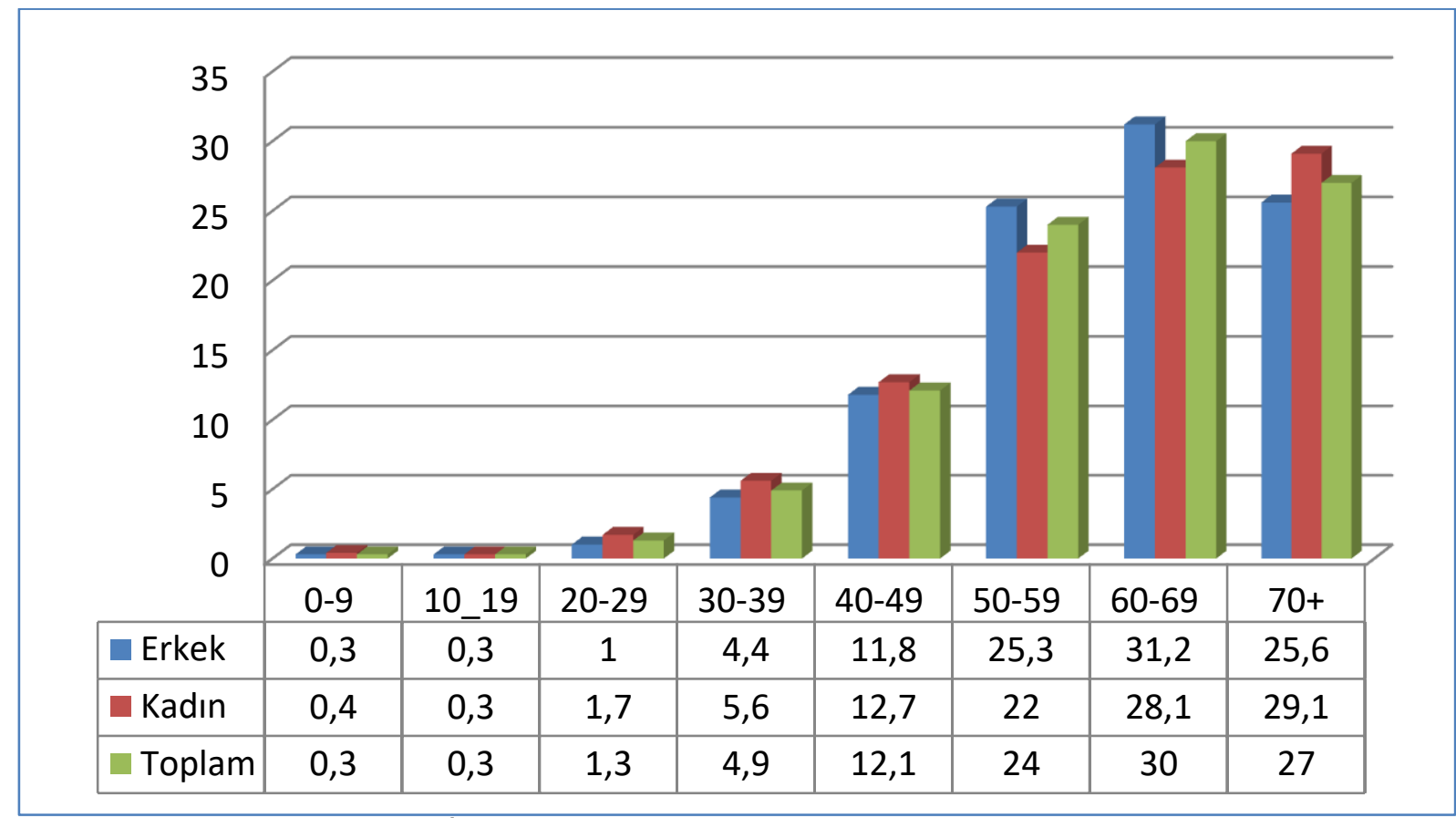

Şekil-4. Gís kanserlerinin cinsiyet ve yaş gruplarına göre dağılımı.

Yirmi yaş ve üzeri erişkin ve çocukluk dönemi karşılaştırmasında çocuklarda en sık yerleşim karaciğer ve intrahepatik safra kanalları iken $(\% 60,9)$, erişkinde kolorektal yerleşim ilk sıradadır $(\% 37,4)$ (Kikare:320,871; $p<0,00019$ ) (Şekil-5).

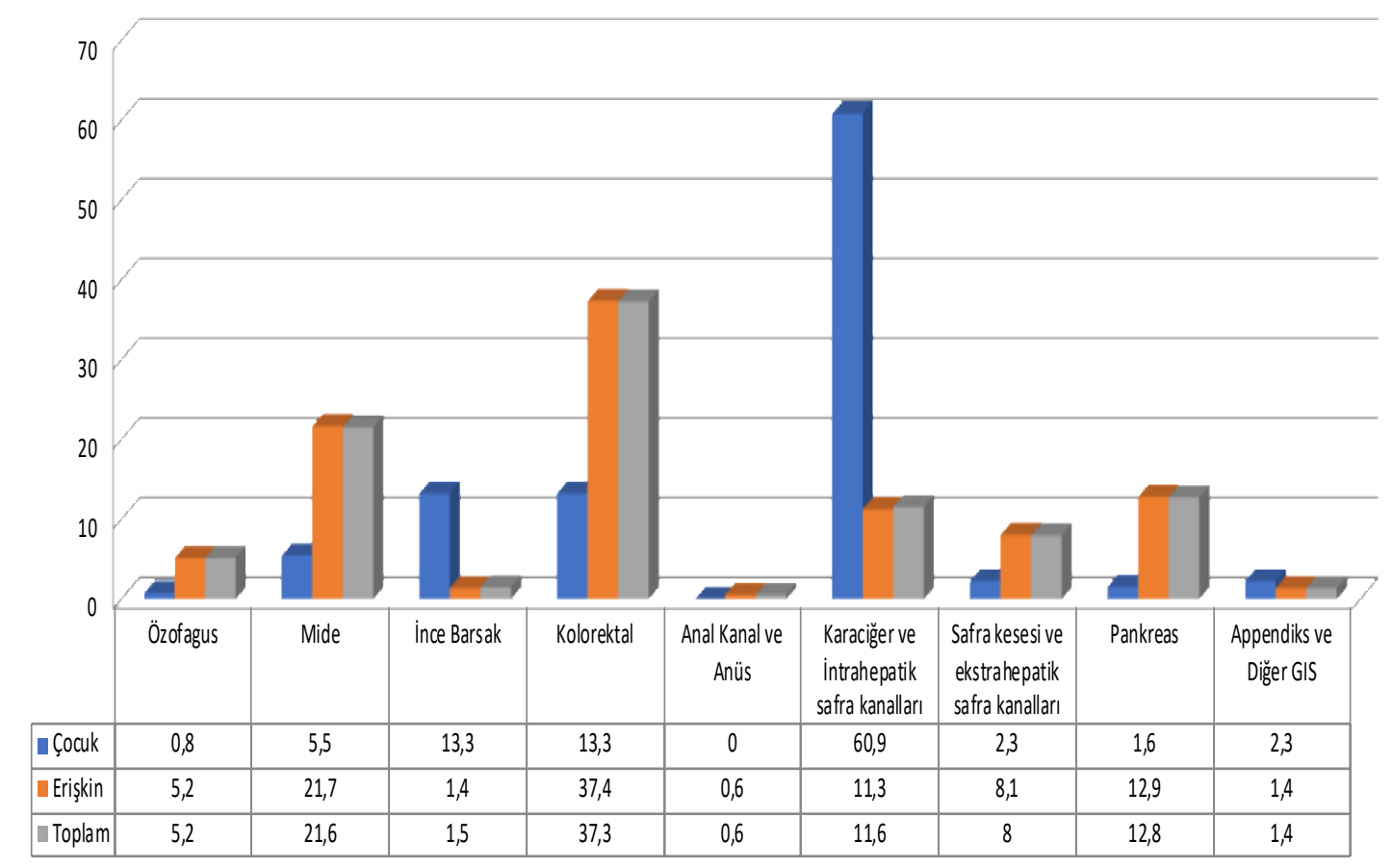

Şekil-5. GiS kanser yerleşimlerinin çocukluk (< 20 yaş) ve erişkin grupta yüzde dağılımları. 
Histopatolojik açıdan en sık adenokanserler (\%70) görülmektedir (Ki-kare=36,591; $p<0,0001)$ (Tablo4, Şekil-6).

Tablo-4. Gis kanserlerinin histopatolojik dağıımı.

\begin{tabular}{lllllll}
\hline Histoloji & Erkek & \multicolumn{3}{c}{ Kadın } & \multicolumn{3}{c}{ Toplam } \\
& $\mathbf{n}$ & $\%$ & $\mathbf{n}$ & $\%$ & $\mathbf{n}$ & $\%$ \\
\hline Adenokarsinom & 5.667 & 70,9 & 3.559 & 68,5 & 9.226 & 69,9 \\
Skuamöz Karsinom & 403 & 5,0 & 366 & 7,0 & 769 & 5,8 \\
Karsinoid & 38 & 0,5 & 36 & 0,7 & 74 & 0,6 \\
Lenfoma & 247 & 3,1 & 203 & 3,9 & 450 & 3,4 \\
Karsinom BBT & 729 & 9,1 & 454 & 8,7 & 1.183 & 9,0 \\
Malign Neoplazm & 709 & 8,9 & 441 & 8,5 & 1.150 & 8,7 \\
Sarkom & 100 & 1,3 & 63 & 1,2 & 163 & 1,2 \\
Nörendokrin & 71 & 0,9 & 47 & 0,9 & 118 & 0,9 \\
Diğer & 31 & 0,4 & 30 & 0,6 & 61 & 0,5 \\
Toplam & $\mathbf{7 . 9 9 5}$ & $\mathbf{1 0 0 , 0}$ & $\mathbf{5 . 1 9 9}$ & $\mathbf{1 0 0 , 0}$ & $\mathbf{1 3 . 1 9 4}$ & $\mathbf{1 0 0 , 0}$ \\
\hline
\end{tabular}

BBT: Başka bir yerde tanımlanmamış.

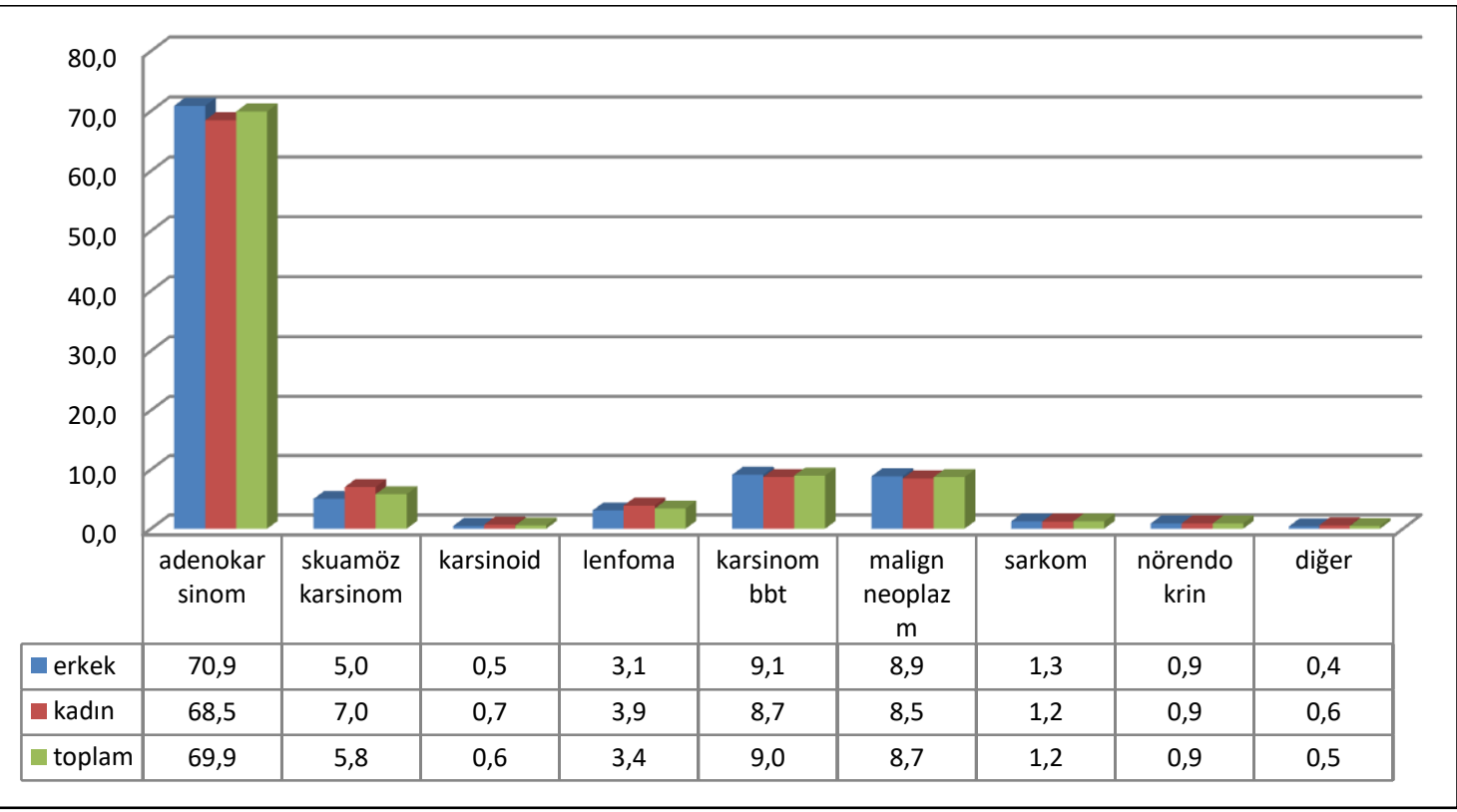

Şekil-6. GiS kanserlerinin cinsiyetlere göre histopatolojik dağılım yüzdesi.

Gis kanserlerinde cinsiyet ve yıllara göre sayıca doğrusal bir artış saptanmıştır (GLM: $F=45,257$; $p<0,0001$ ). Cinsiyetler arası fark anlamlı değildir (Şekil-7). Ayrıca yerleşimlerde yıllara göre artış eğilimi değerlendirildiğinde tüm yerleşimlerde doğrusal artış olduğu dikkati çekmektedir (GLM: $F=45,218 ; p<0,0001$ ) (Şekil-8). 


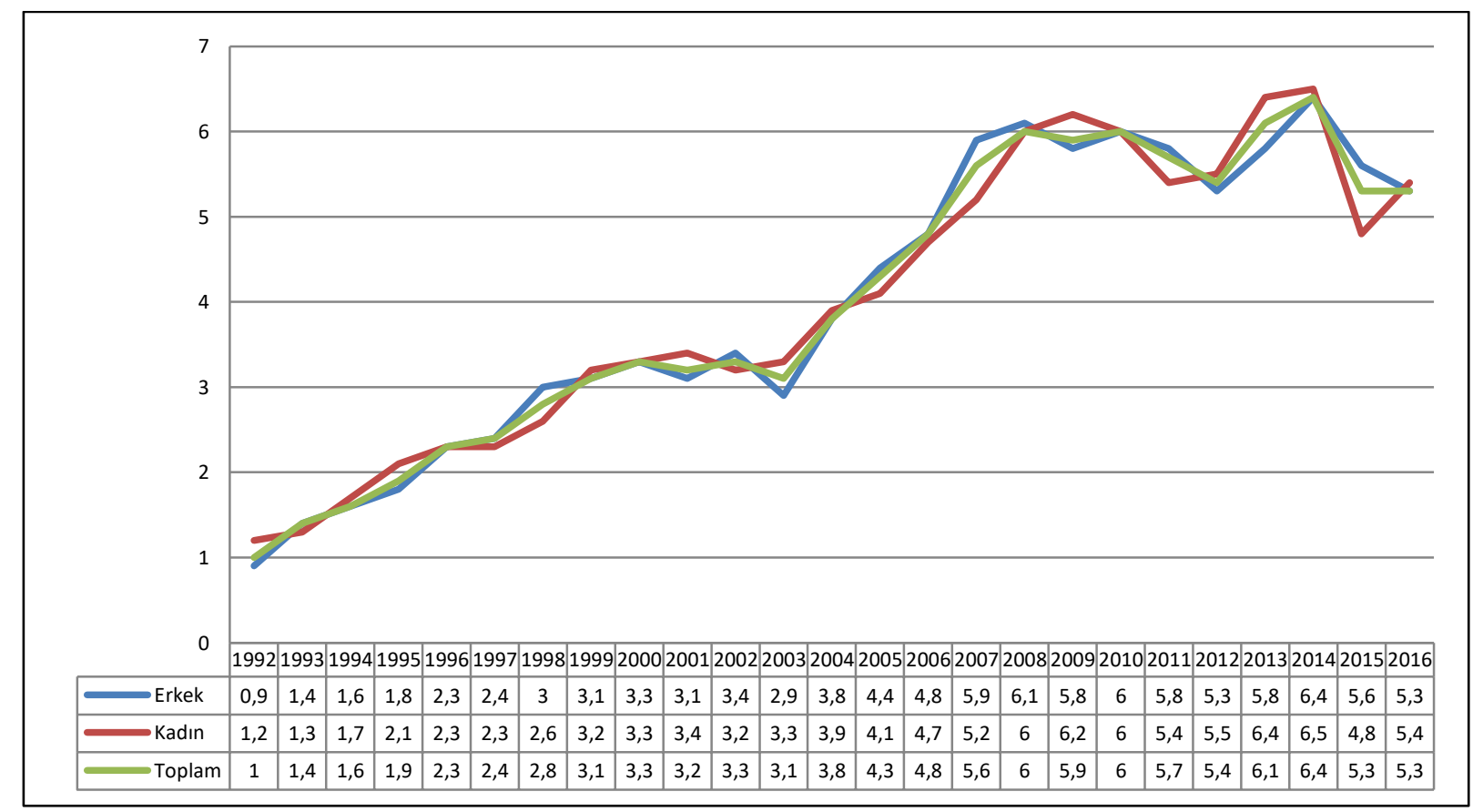

Şekil-7. GiS kanserlerinde cinsiyete ve yıllara göre artış eğilimi.

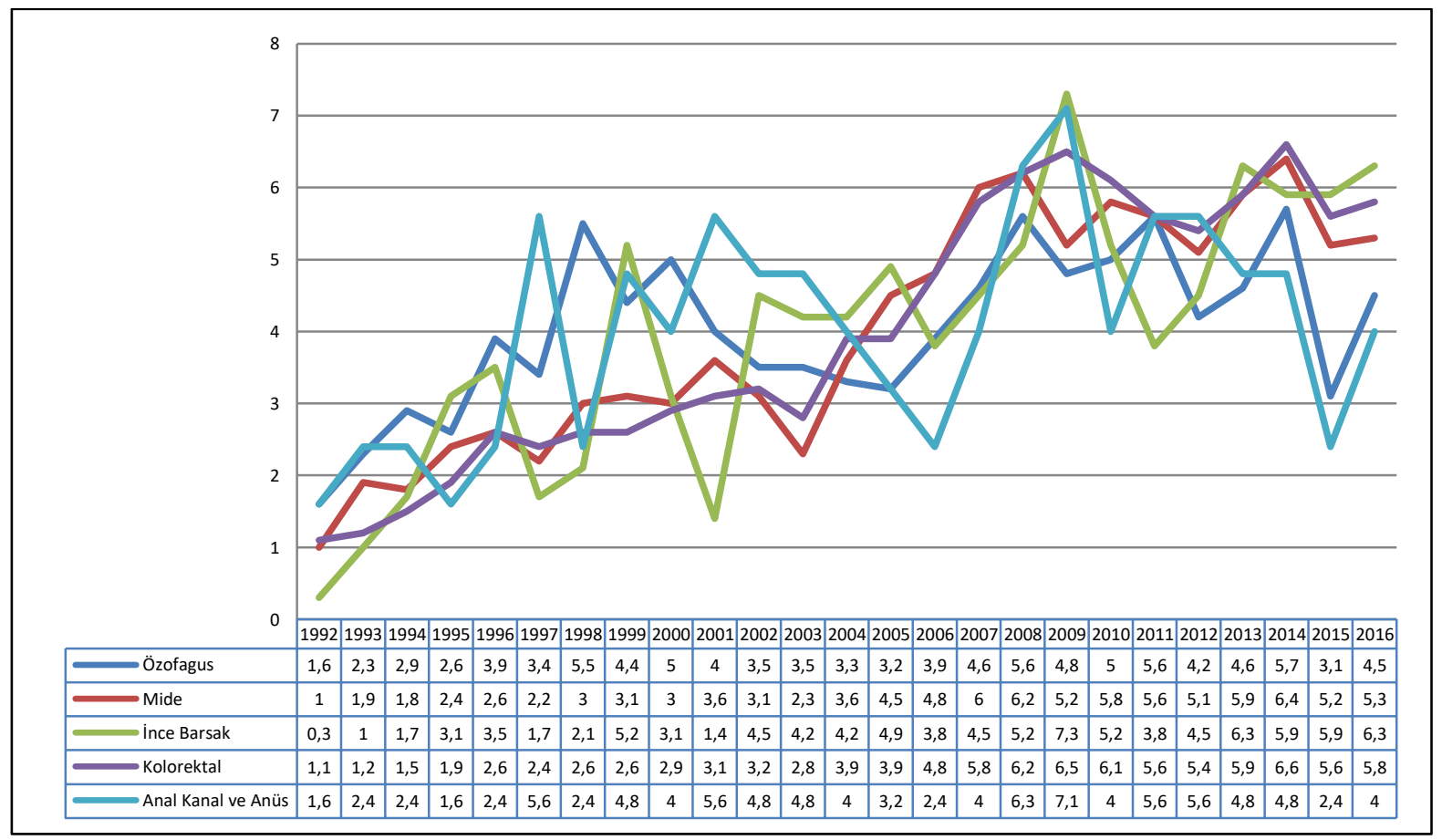

Şekil-8. GiS kanserlerinde yerleşime ve yıllara göre artış eğilimi.

Evrelendirme yapılan olguların daha çok lokal ileri evrelerde tanı aldığı görülmüştür. Evrelere ve cinsiyete göre dağılım Şekil-9'da görülmektedir. 


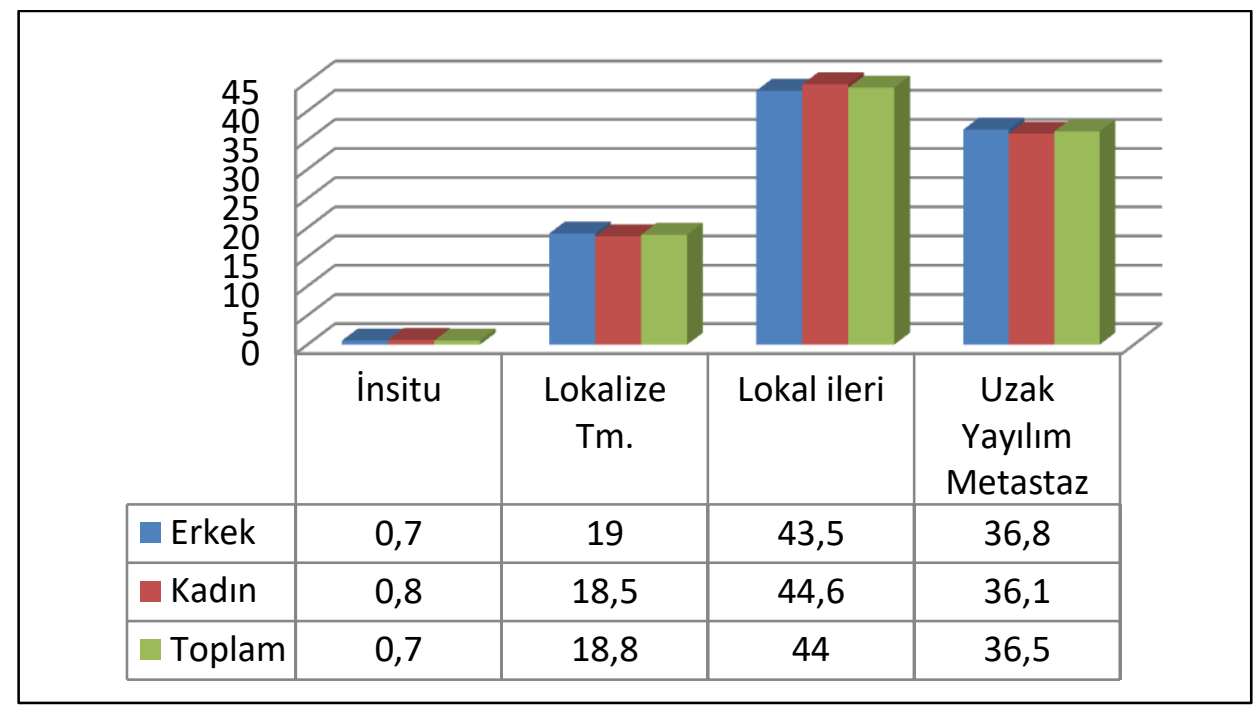

Şekil-9. GiS Kanserlerinde Evrelere ve Cinsiyete Göre Dağılım.

GiS kanserlerimizde ortalama sağ kalım 25 ay, beş ve 10 yıllık GSK oranları \%33,6 ve \%25,2'tir (Tablo-5, Şekil-10).

Tablo-5. Gis kanserlerinde sağ kalım.

\begin{tabular}{cccccc}
\hline & $\mathbf{n}$ & Ölüm $\mathbf{n}$ & Yaşayan \% & $\mathbf{5}$ yıllık sağ kalım & $\mathbf{1 0}$ yıllık sağ kalım \\
\hline Gis & 13.780 & 9781 & 29,0 & 33,6 & 25,2 \\
\hline
\end{tabular}

Cinsiyete göre sağ kalım eğrilerinde kadınlarda prognozun biraz daha iyi olduğu görülmüştür (Şekil-11).

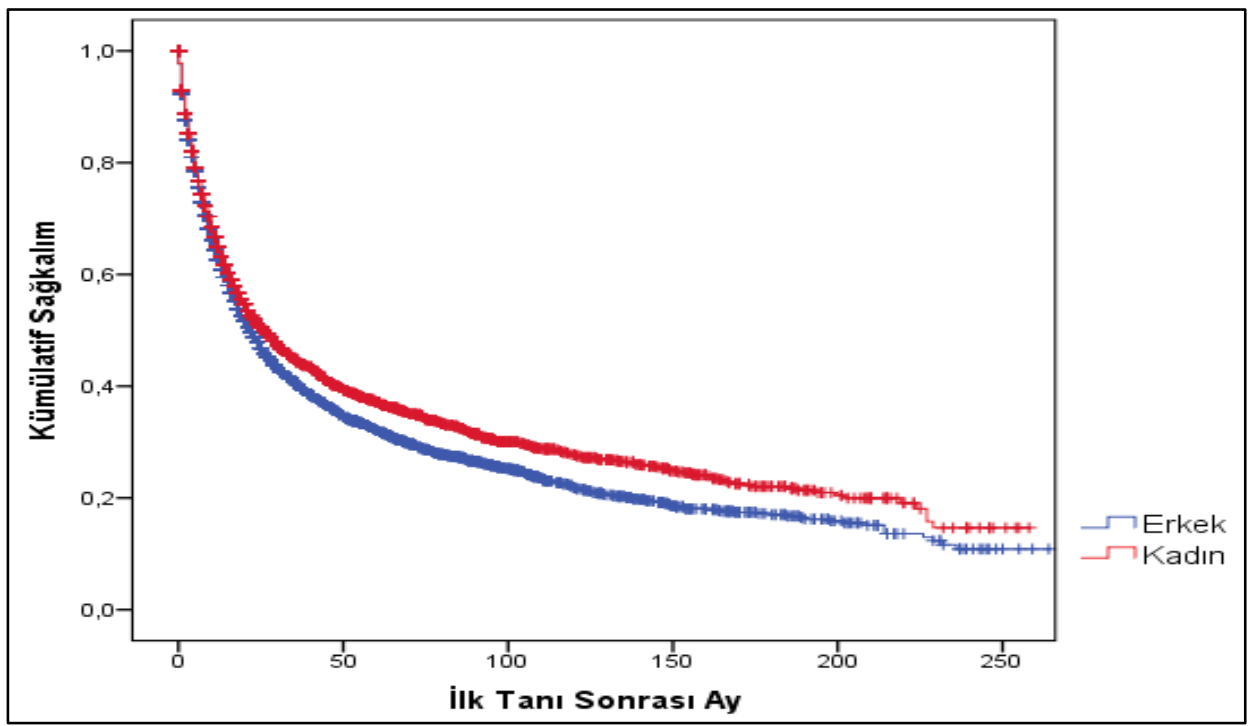

Şekil-10. GiS kanserlerinde cinsiyetlere göre sağ kalım eğrileri.

Yerleşim yerlerine göre en iyi sağ kalım KRK'de (5 ve 10 yıllık GSK oranları sırasıyla \%53 ve \%40), en kötü sağ kalım pankreas kanserlerindedir (5 ve 10 yıllık GSK oranları sırasıyla \%8,3 ve \%6) (Şekil-11). 


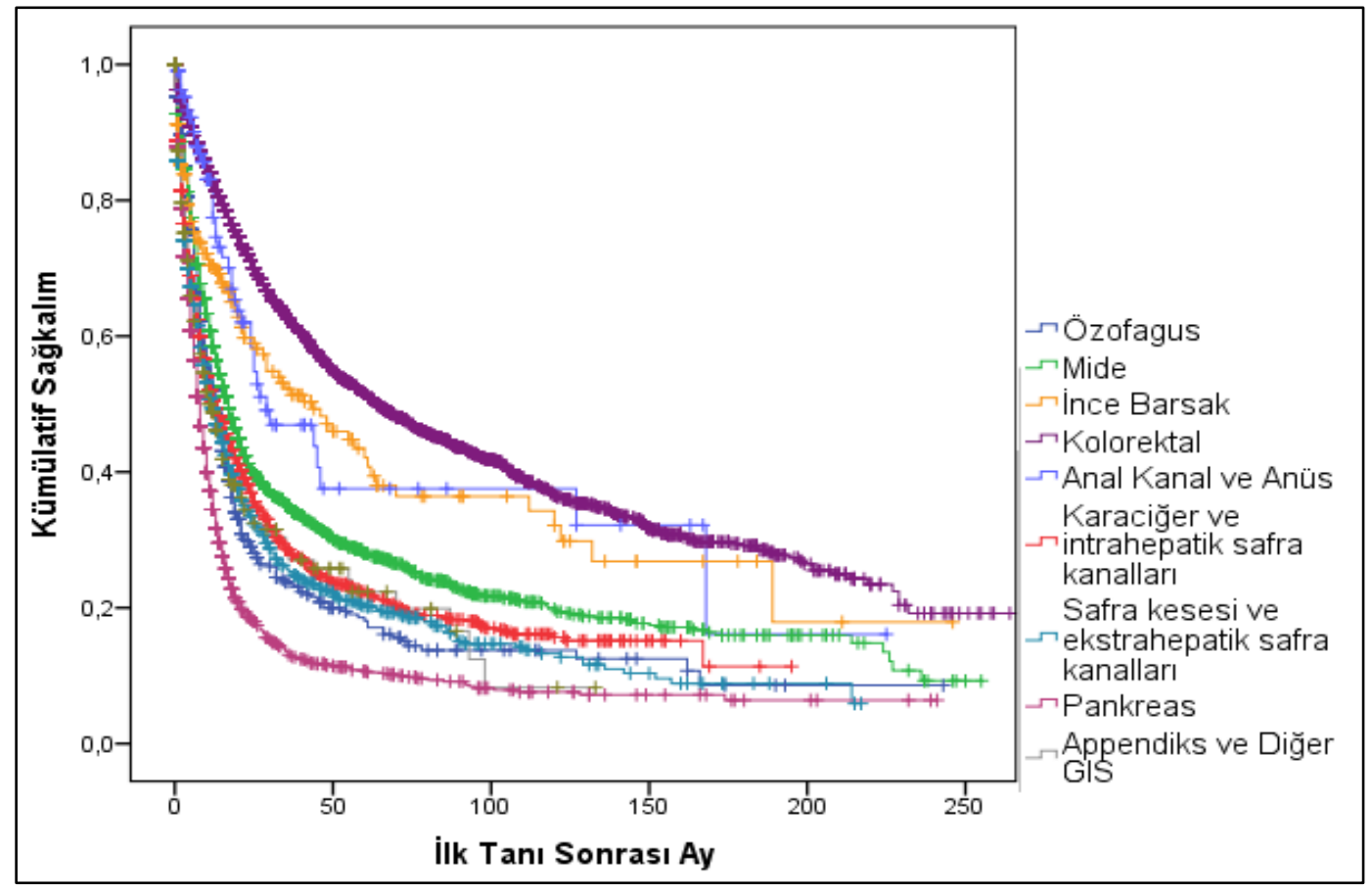

Şekil-11. GiS kanser yerleşimine göre sağ kalım eğrileri.

\section{Tartışma}

GLOBOCAN 2018 verilerine göre total kanser vakalarında birinci sırada \%11,6 ile solunum sistemi kanserleri yer almaktadır (1). Bu kanser tüm kanser ölümlerinin \%18,4'ünü oluşturur. Türkiye kanser istatistiklerinde erkeklerde yaşa göre standardize edilmiş, hızlar (Türkiye Birleşik Veri Tabanı, 2009- 2013) 100.000 kişide 67,6 ile solunum sistemi birinci sırada, 55,6 ile Gis kanserleri ikinci sıradadır. Kadınlarda ise 100.000 kişide 45,9 ile meme kanseri, 31,4 ile Gis kanseri ikinci sıradadır (2). Gis kanserlerinde yerleşimlere göre erkeklerde mide, kadınlarda kolorektal kanserler ön plandadır (2). Bizim serimizde de erkeklerde mide kanseri, kadınlarda ise kolorektal kanserler daha fazladır. Her iki cinsiyeti ele alacak olursak içinde en sık görülen sistem kanserleri \%16,7 ile Gis kanserleridir. Erkeklerde ikinci, kadınlarda üçüncü sırada GiS kanserleri görülürken, her iki cins bir arada değerlendirildiğinde GiS kanserleri birinci sıraya çıkmaktadır.

Avrupa çalışmasında erkeklerde mortalite oranında akciğer kanserini, Gis kanserleri içindeki kolorektal kanserler izlemektedir (3). Bizim çalışmamızda ise erkeklerde akciğer kanserini GiS kanserleri içinden mide kanseri izlemektedir. Avrupa çalışmasında kadınlarda kanser mortalitesinde \%16,2 ile meme kanseri birinci sıradadır. Bunu akciğer, KRK ve pankreas kanseri izlemektedir (3). Amerikan çalışmasında meme kanseri kadınlarda en sık görülen kanserdir ancak mortalitede ABD'de akciğer kanseri birinci sıraya çıkmakta, bunu meme ve GiS kanserlerinden KRK izlemektedir (4). Bizim kadın kanserlerimizde ise ölüme en sık sebebiyet veren meme kanseri \%18'lik bir yer kaplamakta, bunu hemopoetik maligniteler ve jinekolojik kanserler izlemekte, GiS kanserleri kadın kanser mortalitesinde ön sıralarda yer almamaktadır. Kadın olgularımızda, Gis kanserleri daha iyi prognoza sahiptir. Bunun nedeni kadın olguların rektal muayene ve invaziv endoskopik incelemeler gibi kontrol yöntemlerinden kaçınmayıp kontroller konusunda daha uyumlu olmalarıyla açıklayabiliriz. Yerleşim yerlerine göre en iyi sağ kalım kolorektal kanserlerde, en kötü sağ kalım pankreas kanserlerindedir. Amerika'da tüm evreler için KRK'de beş yıllık GSK \%64 iken (5), bu oran erken evrede \%90'lardadır. Avrupa'da beş yıllık GSK \%57 iken (6), Asya ülkelerinde \%31-62 arası değişmektedir $(7,8)$. Bizim serimizde 5 yıllık GSK oranı \%53, erken evrelerde ise $\% 77,4$ bulunmuştur. Pankreas kanserlerinde ise beş yıllık GSK erkeklerde \%11,3'e, kadınlarda \%15,4'e düşmektedir. 


\section{Sonuç}

Sonuç olarak 25 yıllık EÜKAM veri tabanında GiS kanserleri sıklık açısından tüm sistemler arasında birinci sırada yer almıştır. Gis kanserleri içinde en sık KRK ve takiben mide kanserleri izlemektedir ve yıllara göre doğrusal bir artış göstermektedir. GiS kanserlerinde ortalama sağ kalım 25 ay, 5 ve 10 yıllık GSK oranları sırasıyla $\% 33,6$ ve $\% 25,2$ saptanmıştır.
Katkıda bulunanlar: $\mathrm{Bu}$ çalışmada kullanılan verilerde, derginin bu sayısının önsözünde "Teşekkür Listesinde" belirtilen tüm Ege Üniversitesi Tıp Fakültesi Gastroenteroloji Bilim Dalı, Patoloji Anabilim Dalı, Genel Cerrahi Anabilim Dalı, Medikal Onkoloji Bilim Dalı ve Radyasyon Onkolojisi Anabilim Dalı öğretim üyelerinin katkıları olmuştur.

\section{Kaynaklar}

1. Bray F, Ferlay J, Soerjomataram I and et al: Global Cancer Statistics 2018: GLOBOCAN Estimates of Incidence and Mortality Worldwide for 36 Cancers in 185 Countries. Cancer J Clin. 2018; 68: 394-424.

2. Gültekin M, Boztaş G; Türkiye Kanser İstatistikleri. T.C. Sağlık Bakanlığı, Türkiye Halk Sağlığı Kurumu, Kanser Savaş Daire Başkanlığı, 2016.

3. Ferlay J, Steliarova-Foucher E, etal: Cancer incidence and mortality patterns in Europe: estimates for 40 countries in 2012. 2013 Apr; 49(6):1374-403.

4. Siegel RL, Miller KD, Jemal A.CA. Cancer Statistics, 2018. CA CANCER J CLIN 2018; 68: 7-30.

5. American Cancer Society. Cancer Facts \& Figures 2019. Atlanta, Ga: American Cancer Society; 2019.

6. De Angelis R, Sant M, Coleman MP, et al. Cancer survival in Europe 1999-2007 by country and age: results of EUROCARE-5 - a population-based study. Lancet Oncol 2014; 15: 23-34.

7. Yeole BB, Sunny L, Swaminathan R, Sankaranarayanan R, Parkin DM. Population-based survival from colorectal cancer in Mumbai, (Bombay) India. Eur J Cancer. 2001Jul; 37 (11): 1402-8.

8.Park YJ, Park KJ, Park JG, Lee KU, Choe KJ, Kim JP. Prognostic factors in 2230 Korean colorectal cancer patients: analysis of consecutively operated cases. World J Surg. 1999 Jul; 23 (7): 721-6 